\title{
ESCOLA - FAMÍLIA - COMUNIDADE: UMA RELAÇÃO PARA O SUCESSO EDUCATIVO
}

\author{
Maria Martins de Sousa ${ }^{I}$, Teresa Sarmento ${ }^{2}$
}

\begin{abstract}
Resumo: Este artigo faz uma abordagem à problemática da relação entre a escola e as famílias e a sua correlação com o sucesso escolar, numa perspectiva multifocal, isto é, na convicção generalizada da premência do estabelecimento e desenvolvimento duma relação de cooperação, sem deixar de tomar consciência das vicissitudes, enviesamentos e entropias negativas que têm dificultado a concretização de um verdadeiro envolvimento das famílias com a escola, no sentido do cumprimento duma missão que às duas instituições é reconhecida e indiscutivelmente comum - o sucesso na formação escolar e desenvolvimento pessoal de crianças, adolescentes e jovens. Numa perspectiva optimista, são apresentadas as potencialidades do desenvolvimento positivo desta relação de colaboração, bem como algumas estratégias que vêm sendo apontadas pela literatura.
\end{abstract}

Palavras - Chave: Educação, Escola, Família, Comunicação, Parceria, Envolvimento.

\begin{abstract}
This article presents an approach to the relationship between schools and families and its correlation with school success, in a multifocal perspective, that is, in the generalized conviction of the urgency of establishing and developing a cooperative relationship, while awareness of vicissitudes, entropies and negative biases that have hindered the attainment a true involvement of family with school, towards fulfilling a mission that is recognized and arguably common to both institutions - success in school and personal development of
\end{abstract}

\footnotetext{
1 Mestranda em Ciências da Educação, Universidade Católica - Viseu. E-mail: mariamartinssousa@gmail.com

2 Professora Auxiliar, Instituto de Educação - Universidade do Minho. E-mail: tsarmento@ie.uminho.pt
} 
children, adolescents and young. From an optimistic perspective, the potential of the positive development of this collaborative relationship is presented, as well as some strategies that have been pointed in literature.

Keywords: Education, School, Family, Communication, Partnership, Involvement

\section{1 - INTRODUÇÃO}

A realidade institucional escolar constitui uma actividade de cariz eminentemente social. Foram necessidades e interesses de ordem social, política, económica e cultural que determinaram a sua emergência e desenvolvimento, continuando a ser o seu sustentáculo e a sua pauta de referência e de exigência.

Pelas exigências impostas à escola, a sociedade sempre influenciou o seu funcionamento, sendo hoje verdade, talvez mais do que nunca, que a escola também tem uma grande influência nessa mesma sociedade, consubstanciando uma realidade cada vez mais presente na criação e desenvolvimento de expectativas e aspirações, pela criação e desenvolvimento de competências necessárias à promoção da qualidade de vida das crianças e jovens e, consequentemente, pela determinação dos ciclos de vida das populações. Ballenato considera ser a partir da educação que se constrói a sociedade, constituindo aquela "a pedra basilar sobre a qual assenta a convivência, o bemestar e o progresso social" $(2009,27)$. Com efeito, face aos múltiplos desafios do futuro, a educação surge como um trunfo indispensável à humanidade, pelo seu papel essencial no desenvolvimento contínuo das sociedades, constituindo a educação escolar, uma necessidade e uma exigência à qual não é possível nem desejável escapar. Para Elizabete Lawrence (n.d., 11) "num mundo difícil, em que é difícil manter o equilíbrio, a escola é aceite como uma sentença comum a todos, que tem de ser cumprida antes de se poder entrar livremente no mundo...".

Numa sociedade multicultural, altamente competitiva, exigente e selectiva como a actual, que evolui continuamente de forma dinâmica, e na qual se inscreve a acção educativa, construída por influência de contextos vários, cabe à escola a responsabilidade de se multiplicar em estratégias e acções, reinventando-se permanentemente para ajudar os alunos a desenvolver competências essenciais com vista à sua promoção pessoal, social e profissional. Assim, considerando como finalidades da educação escolar a formação pessoal, a integração social e a estimulação, a escola depara-se com a necessidade de romper com a chamada "escola tradicional", centrada em si mesma, e a premência de uma verdadeira relação de parceria com a família, partindo da 
premissa, irrefutável, de que esta constitui a primeira e permanente responsável e promotora da formação global do seu educando.

\section{2 - EDUCAÇÃO LATO SENSU ${ }^{3}$}

Sendo possível, segundo Montandon e Perrenoud (2001, 5), tantas concepções de educação quantas as percepções e representações da ordem social e do papel e função do indivíduo nesse mesmo sistema social, parece-nos útil a apresentação do conceito através da perspectiva de alguns autores.

Segundo Nérice (n.d., 9), a palavra educação provém do latim - educatione e surgiu no início do século XVI, designando etimologicamente o acto de educar, na dupla valência de educare (alimentar) e educere (tirar para fora de, conduzir para...).

No Dicionário de Língua Portuguesa da Porto Editora (n.d.), educar é apresentado como o acto de fornecer o necessário para o processo que visa o desenvolvimento harmónico do homem nos seus aspectos intelectual, moral e físico e a sua inserção na sociedade. Nesta perspectiva, educar é, então, plataforma para o devir; é carta de socialização, como processo de aquisição de conhecimentos, valores e símbolos, ou seja, das maneiras de ser, pensar e agir - a cultura - do grupo em que o indivíduo está inserido. Educar é modificar num sentido determinado, isto é, conduzir de um estado para o outro, sendo que o postulado implicado na educação é a educabilidade, virtualidade do homem para perseverar no seu ser e adquirir experiência.

Em termos escolares, a educação visa ajudar o aluno, através das matérias e programas, a conseguir um conjunto de atitudes e aptidões que o colocam como sujeito activo na sociedade. Já em linguagem corrente, o termo educação tem a ver com o resultado de uma acção na qual a pessoa se revela bem ou mal educada. O termo, assim, está concebido como produto de todo um processo que remonta ao nascimento da pessoa, sujeita aos vários condicionalismos.

Cada paradigma educacional está subjacente a um modelo de sociedade, sendo a educação o veículo através do qual essa sociedade tenta passar para as gerações futuras o melhor que tem, condicionando este processo dinâmico em ordem a um conjunto de valores. Assim, segundo Savater (1997, 106),

"a educação transmite porque quer conservar e quer conservar porque valora positivamente certos conhecimentos, certos comportamentos, certas habilidades, certas ideias. Nunca é neutral;(...). Tenta favorecer um tipo de homem (...), um modelo de cidadania, de sistema laboral, de maturação psicológica (...) que não é o único possível, mas que considera preferível a outros".

\footnotetext{
${ }^{3}$ Neste contexto, o termo educação é utilizado num sentido global, que inclui o sentido estrito de educação escolar e o conceito mais abrangente de educação.
} 
Na mesma linha de intencionalidade do acto educativo, Ulmann (1982, 9-26) defende que a educação consiste numa acção exercida por um ser humano sobre outro ser humano - mais frequentemente por um adulto sobre uma criança - de modo a fazer com que o educando adquira certos traços culturais que os costumes, sentimentos ou convicções consideram como desejáveis. Neste sentido, pode definir-se educação como o conjunto de processos geralmente dirigidos pelos adultos que, voluntária e intencionalmente, desenvolvem as potencialidades do ser humano para o levar a desempenhar um papel activo e responsável na sociedade em que vive.

De facto, como processo integral, a educação, nomeadamente a educação formal, atinge o homem em todas as suas dimensões: física, mental, psíquica, social, intelectual, estética e moral. Dewey (1859-1952) - considerado como o filósofo da educação moderna - defende que no processo que é a educação, deve apostar-se sobretudo na pessoa e no seu desenvolvimento integral, devendo esta ser entendida como um fim e não como um meio, com vista à sua realização como ser social, sempre no respeito pela singularidade de cada indivíduo. Um dos autores mais importantes do movimento norte-americano de educação progressista, Dewey acredita no poder libertador da educação e considera que "um sistema público de qualidade é um poderoso instrumento de combate às desigualdades sociais, acentuando o papel da escola na educação dos alunos para o exercício da cidadania" (como citado em Marques, 1999, 143). Utilizando um conceito abrangente do mesmo autor, Carneiro (2001, 49), afirma que a educação "não é uma preparação para a vida, mas é a própria vida". Numa perspectiva de grande optimismo, Carneiro (id., 11-18) lembra a fonte inesgotável de expectativas e de aspirações humanas que representa a educação, enquanto "agente civilizador" e sublinha que, perante tanta indeterminação e até sintomatologia de crise, a educação pode fazer a diferença, nela se devendo ancorar as nossas expectativas em relação ao futuro. Sem deixar de referir a necessidade absoluta de reorganização da instituição escolar, face às tensões sem precedentes a que a função educativa é submetida nesta "era de descontinuidade", e recordando que aquela espelha todas as contradições da sociedade, exorta-nos a constatar que é sobre a educação que "repousam todas as esperanças de melhoria da sociedade futura".

Embora o termo tenha surgido apenas no início do século XVI, a questão da educação, como facto primordial da humanidade, foi sempre uma das preocupações do homem, dizendo-se popularmente que ela é tão antiga como ele próprio. No entanto, ao longo dos tempos, a educação foi sofrendo alterações e especializações decorrentes de influências, quer filosóficas, quer sociais, de cada época, o que faz dela uma realidade dinâmica. Sendo, a um tempo, produto e factor da própria sociedade, a educação corresponde sempre a uma realidade 
socialmente situada "num tempo e num espaço históricos específicos." (Trindade \& Cosme, 2010, 17).

\section{3 - A FAMÍLIA: DA PLURALIDADE DE FORMATOS À UNIDADE DE FUNÇÕES}

Segundo Leandro (2001, 38), etimologicamente, a noção de família tem origem no vocábulo latino famulus, que significa servidor. No entanto, no sentido aproximado à definição moderna que lhe conhecemos hoje, o termo aparece apenas no século XVII. Segundo o mesmo autor (id., 39), a família tornou-se um conceito polissémico, dada a sua grande diversidade de estruturas, organizações e representações, pelo que, o mais adequado parece ser, como aconselha Roussel (1992), "não se falar de família a não ser no plural." (Como citado em Diogo, 1998, 72).

O Dicionário Houassis da Língua Portuguesa (2003) apresenta o termo família como correspondendo a "um grupo de pessoas vivendo sob o mesmo tecto" ou que estão " ligadas entre si pelo casamento e pela filiação ou, excepcionalmente, pela adopção”. São apresentadas algumas tipologias, dependendo quer dos elementos que a constituem quer da natureza dos laços entre eles existentes. Assim, fala-se de família natural, família nuclear, ou, ainda, de família substituta. Vários autores acrescentam outros formatos, como a família monoparental, família de adopção, família recomposta, uniões de facto ou família homossexual (esta legitimada em Portugal, a partir da Lei nº 9/2010, de 31 de Maio).

Embora a instituição familiar tenha vindo a sofrer grandes alterações em termos de conceptualização, devido às dinâmicas, mutações e rearranjos que em si se têm verificado, é do senso comum percepcioná-la como um grupo, mais ou menos nuclear, de indivíduos unidos por laços habitualmente de sangue, constituindo-se como o primeiro contexto onde a criança constrói as suas primeiras experiências de interacção, isto é, onde a criança desenvolve a sua socialização primária.

Estando a sua primeira grande transformação ligada ao processo de expansão da sociedade industrial, que afectou quer a sua estrutura e composição, quer as suas funções e relações (Dias, 2000, 89 - 95), o certo é que em cada época, uma sociedade, ao dar prioridade a determinados valores, determina modelos de convivência diferentes e, consequentemente, organizações familiares específicas. Ballenato $(2009,31,32)$ aponta como determinantes nas transformações familiares modernas, factores sociais que passam pela progressiva integração da mulher no mundo do trabalho, o aumento da taxa de divórcios, o processo de urbanização, os estilos de vida consumistas, a diminuição da taxa de natalidade, a difusão das novas tecnologias de informação e o aumento do fenómeno da imigração, a que Sousa $(1998,104)$ acrescenta "a realidade económica 
debilitada, (...)" e "algumas inovações médicas". A conjugação destes e de outros factores potenciou, nas últimas décadas, um movimento de proliferação e concomitância de múltiplos modelos de estruturas e convivências familiares, pondo em causa o modelo de família dominante até aos anos 50 do século passado e dando origem, àquilo a que Roussel (1989) designou de "família incerta". (como citado em Diogo, 1998, 73).

Enquanto "quadro mais favorável para a educação das crianças e dos jovens e para a sua inserção na vida" (Porto, 2005, 15), à família sempre foi socialmente atribuído um considerável número de funções e responsabilidades em relação aos seus membros, que, segundo Ballenato $(2009$, 233), passam pela coabitação, responsabilidade económica, a afectividade, a reprodução, bem como a protecção, socialização e educação dos seus descendentes, características e funções que, embora em diferentes graus de efectividade, se mantêm em todos os modelos familiares.

No contexto em análise, registe-se que é com esta pluralidade e heterogeneidade de tipologias e modelos que enforma a realidade familiar que a escola se relaciona, facto que contribui, certamente, e em larga medida, para a enorme e reconhecida complexidade que caracteriza essa relação. A este propósito, parece-nos pertinente referir o raciocínio de Sá $(2004,110)$ que, ao discorrer sobre as tipologias de envolvimento dos pais apresentadas segundo a perspectiva da escola, denuncia e crítica, nessa mesma tipificação, o não reconhecimento e, consequentemente, a não consideração, das profundas transformações nas estruturas e dinâmicas familiares. Acrescenta este autor que essa subtracção leva a que seja ignorada a desadequação de certas formas de envolvimento que, em última análise, podem "ir em contra-corrente" em relação a essas mutações familiares.

Na opinião de Villas-Boas (2001, 61), a família, independentemente da sua constituição, sempre poderá ser entendida como um sistema, uma vez que ela não é o resultado do somatório dos elementos que a constituem, antes se apresentando como o produto das interacções entre os mesmos, nomeadamente no que respeita a afectos e ao desenvolvimento da auto-imagem.

Face à escola, e seja qual for a tipologia de família, esta deverá ser, sempre, entendida como a instituição à qual cabe a primeira e permanente responsabilidade pela educação e formação da criança.

\section{4 - ESCOLA/FAMÍLIA: UMA RELAÇÃO DIFÍCIL, MAS QUE URGE CONSTRUIR}

Durante anos, a escola constituiu-se como um espaço fechado e à margem da comunidade, uma vez que lhe competia apenas a função de instrução, o que lhe permitia comportar-se como uma sociedade dentro da sociedade geral. Em consequência deste comportamento insular da escola, a sua relação com a 
comunidade desenvolveu-se essencialmente num registo negativo: as famílias só eram chamadas à escola quando havia problemas com os filhos e "só eram convidadas para actividades em que tinham um papel meramente de espectador" (Marujo et al.2005, 149). A escola não via com bons olhos a vinda à escola por parte dos pais mais interessados, entendendo essa atitude de intervenção como uma ameaça ao exercício das suas funções. Por outro lado, a família tinha tendência para percepcionar a escola de forma crítica e desinvestida, pedindo apenas contas relativamente ao insucesso, que prontamente justificava com erros de métodos ou de conteúdos. Em meados do século XX foi notório o aumento de importância atribuído à escolarização, levando essa sua crescente importância política e social ao consequente aparecimento de novos problemas e desafios à instituição escolar, decorrentes, nomeadamente, da sua massificação. Assim, apresenta-se como fundamental a interacção positiva da escola com a família, por forma a desenvolver-se uma relação colaborativa entre estas duas instituições mutuamente responsáveis pelo prosseguimento adequado do processo de escolarização e educação. Mais de trinta anos passados sobre a publicação da Lei $\mathrm{n}^{\mathrm{o}} 7$, de 1 de Fevereiro de 1977 (Silva, 2003, 141), que legitima a participação dos pais e encarregados de educação na vida e gestão escolares, e depois de um longo percurso de ascendência legislativa no que concerne a essa legitimação, apresenta-se hoje cada vez mais necessária uma intervenção educativa assente numa dinâmica de interacção e co-responsabilização entre as várias instâncias educativas em que a criança vivencia experiências, equacionando-se, por conseguinte, uma formação global na qual a educação para a cidadania desempenha um papel de destaque. Assim, sendo esta interacção multidimensional de importância capital para o desenvolvimento de todas as crianças e jovens, exige-se que os pais estejam atentos e se envolvam positivamente na vida escolar dos filhos. À escola, por seu turno, enquanto sistema que deve tender para a prática de um novo modelo mais aberto que aceita os seus novos desafios e conflitos como factores de mudança e de progresso, compete incentivar e promover esse envolvimento, estabelecendo canais diversificados de comunicação e colaboração que funcionem em regime permanente de confiança mútua e, através de estratégias adequadas e significativas para as famílias, chamá-las à escola, no sentido do desenvolvimento de relações positivas entre estas duas instituições às quais cabe a partilha de responsabilidades na educação e formação das crianças e jovens.

Sendo vários os estudos publicados (Canário, 2009; Diogo, 1998; Marques, 2001 b; Silva, 2003; Villas-Boas, 2001) que evidenciam a existência de uma correlação forte e positiva entre os resultados escolares, a assiduidade e o comportamento dos alunos e a existência e qualidade do envolvimento das famílias, é hoje consensual a necessidade vital de se estabelecer e desenvolver uma cooperação estreita entre a escola e a família, sob pena de se não cumprirem os objectivos esperados da função educativa. Na esteira de Seeley (1985), e 
enfatizando, igualmente, a necessidade de cooperação entre a escola e as famílias, Villas-Boas $(2009,47,48)$ afirma que a explicação para o insucesso dos alunos, a existir, deverá ser procurada, não na escola, nem na família, isoladamente, mas na falta de uma "relação produtiva de aprendizagem entre ambas.".

Autores como Marujo, Neto e Perloiro $(2005,11)$ consideram que, para além de um direito, o envolvimento dos pais na educação escolar é uma responsabilidade e um valor. Assim, tendo como referência os sistemas família e escola, e partindo da evidência de que o indivíduo é simultaneamente filho, aluno e cidadão, uma vez que, tal como defende Costa $(1998,9)$, “a educação possui um carácter eminentemente social que lhe advém da existência de vários actores sociais com funções educativas (...)", assume-se que a educação compete, simultaneamente e sem subalternidades, a pais, professores e sociedade em geral.

\section{5 - BENEFÍCIOS DO ENVOLVIMENTO PARENTAL NA VIDA ESCOLAR DOS SEUS EDUCANDOS}

Como acima referido, a acção educativa é tarefa de toda a sociedade, de todas as instâncias educativas por onde passa a criança. No entanto, tal como igualmente registado, ninguém nega a evidência de que à família cabe a primeira e permanente responsabilidade de orientar e desenvolver competências que permitam a construção de um projecto de vida consentâneo com as suas potencialidades e aspirações. Ballenato $(2009,16-17)$ reforça a importância do período de treino para viver que representa a infância, alertando para o facto de muito do que se passará no seu futuro estar altamente condicionado por este primeiro período da sua experiência vital. É em contexto familiar que se desenvolvem as competências para o exercício da cidadania, que se adquire um quadro de referências culturais que servirá de pauta de leitura das relações e interacções sociais. Assim se compreende que a escola não poderá desempenhar verdadeiramente o seu papel se não puder contar com o apoio da família. É esta quem melhor conhece as potencialidades, as características específicas de cada aluno, sendo, por isso, o actor mais bem colocado para subvencionar a escola e os professores de informações fundamentais para o desenvolvimento de projectos e estratégias mais adequadas, continuando os pais a ser os primeiros, permanentes e mais importantes professores das crianças.

O sucesso educativo das crianças e jovens está positivamente relacionado com a forma como a escola e a família encaram e desenvolvem essa missão comum. Cientes de que o grau e tipo de envolvimento das famílias depende directamente da representação que estas têm da escola, estamos convictos de que é fundamental promover essa colaboração, pois a vida da escola e das famílias será francamente melhorada e facilitada se houver um verdadeiro espírito de colaboração em torno da vida escolar das crianças, uma vez que terá um impacto 
muito positivo na sua integração, motivação e desempenho. Pedro Silva (2009, 116) lembra a consistência da investigação ao considerar que "quanto mais estreita a relação entre escolas e famílias, maior o sucesso educativo das crianças e jovens." e que a literatura faz abundante referência aos benefícios desta relação, para além do sucesso escolar dos alunos. Assim, o autor (id., 116119) refere que, do envolvimento das famílias, sai reforçada a satisfação profissional dos professores, uma vez que o objectivo do seu esforço é o eficaz aproveitamento dos alunos; os pais sentem-se socialmente valorizados, o que constitui um factor de considerável importância nas classes populares, levando a um reforço do papel das associações de pais e da sua legitimação social; as comunidades, por sua vez, também são beneficiadas, na medida em que esta colaboração com a escola pode contribuir para a construção da sua identidade. Acrescenta, ainda, que o estreitamento das relações entre escola, família e comunidade, ao implicar uma atitude de comunicação e participação dos vários actores, induz a uma cultura de cidadania e a um aprofundamento democrático, quer a nível representativo, quer participativo. E porque se aprende a colaborar, colaborando, nota o mesmo autor $(2003,355)$ o facto de toda essa prática consubstanciar um aumento da democratização da escola e da comunidade envolvente, sublinhando o papel mobilizador que a escola pode desempenhar nas comunidades, enquanto agência de desenvolvimento das mesmas.

Na mesma linha, Sousa $(1998,148-150)$ recorda que a literatura apresenta recorrentemente o envolvimento dos pais com a escola associada a múltiplas vantagens. A criança (aluno na escola, filho em casa e cidadão na comunidade) sente-se mais motivada e posiciona-se mais positivamente em relação à escola e à sua aprendizagem, o que potencia o seu sucesso, sendo as crianças em risco as que mais podem beneficiar com esse envolvimento; os pais, ao sentirem-se apoiados, vêem elevadas a sua motivação e auto-estima, uma vez que se alargam as redes sociais que proporcionam o acesso a mais informação e apoio entre si; os professores, perante as atitudes positivas dos pais, que lhes fornecem mais e melhor informação sobre os alunos, vêm o seu trabalho facilitado e a sua satisfação aumentada; no respeitante à comunidade, podem ser significativos os ganhos em termos do desenvolvimento de valores de igualdade e democracia, para além da melhoria da qualidade das opções e da coordenação dos seus serviços; a instituição escolar, ao descentralizar-se e aproximar-se dos outros actores, melhora os padrões de qualidade educativa.

Conclui-se, pois, que, a concretização de uma relação de parceria entre a escola, as famílias e a comunidade, consubstancia uma realidade da qual são evidentes os benefícios para todos os intervenientes. 


\section{6. - DESOCULTAR OBSTÁCULOS/ADEQUAR ESTRATÉGIAS}

Não se pode, no entanto, considerar ou esperar que seja fácil esta relação entre a escola e as famílias, por uma miríade de razões, entre as quais se ressaltam as descontinuidades culturais. Silva $(2009,21)$ caracteriza a cultura escolar como uma cultura "letrada, urbana e de classe média, correspondendo à cultura socialmente dominante", o que pode constituir uma barreira a ultrapassar, uma vez que a sua população discente provém de estratos sociais e culturais multifacetados. Refere o mesmo autor que, mais importante do que "aceitar $e$ promover uma escola multicultural, será a construção de uma escola intercultural", sendo que, a sua relação com as comunidades, ao subtrair por desconhecimento ou incompetência essa multiplicidade, pode consubstanciar a replicação e agravamento da clivagem social já existente, tornando-a num instrumento fomentador de exclusões sociais, nomeadamente sob a forma de insucesso e/ou abandono escolar.

Outro constrangimento ao estabelecimento de uma relação saudável entre a escola e as famílias pode advir do receio que os professores revelam em aceitar verdadeiramente os pais como seus parceiros neste processo de formação das crianças. Os professores, que têm geralmente uma opinião negativa sobre as competências educativas das famílias, revelam tendência para encarar a participação e envolvimento dos pais como uma ameaça ao seu estatuto e uma ingerência negativa no seu trabalho. Na opinião de Lima $(2002,8)$, a propósito da participação dos pais nos órgãos de gestão das escolas, "nunca como agora os professores sentiram o seu espaço de acção tão desprotegido, em relação à sua invasão literal por parte dos encarregados de educação". Para além disso, as expectativas dos professores relativamente à participação dos pais têm sempre como base um modelo ideal de família que, em sintonia cultural com a escola, compreende o seu funcionamento e tem facilidade em participar, levando a que a invisibilidade dos outros pais na escola seja por eles interpretada como desinteresse pela vida escolar dos filhos. Diogo, Serpa, Caldeira, Moniz e Lopes (2002), reflectindo sobre a ineficácia das directivas centrais no respeitante ao incentivo à participação dos pais, concluem que os professores, apesar de reconhecerem as vantagens educativas associadas à participação dos pais na vida escolar dos filhos, "ainda sentem dificuldade, ao nível das práticas, em promover estratégias que facilitem e tornem eficaz a cooperação com as famílias" (citado em J. Lima, 2002, 20).

Por seu turno, os pais, para além duma atitude de desconfiança face ao papel dos professores, têm, muitas vezes, paradoxalmente, a opinião de que a estes e à escola cabe a total responsabilidade de educar os seus filhos, delegando neles todas as competências para o efeito e demitindo-se da sua responsabilidade de primeiros e permanentes educadores. Esta duplicidade que caracteriza o comportamento dos pais em relação à escola (Sá, 2004, 17) advém do facto de os 
mesmos pertencerem a níveis e estratos sociais diversos. Os pais têm culturas diferentes, formações académicas distintas e, por conseguinte, diferentes expectativas e atitudes face à escolarização dos seus filhos, o que, naturalmente, influencia a sua relação com ela e torna, no dizer de Montandon e Perrenoud (2001, 4), "difícil dosear a abertura da escola aos pais.".

As características organizacionais e funcionais da escola são, igualmente, apontadas pela literatura como uma barreira à participação e envolvimento das famílias. À forma rígida e centralizada de funcionamento, acresce a desadequação dos espaços e dos horários de atendimento aos pais; a falta de um espaço gerido por estes, onde se possam encontrar informalmente e planificar a sua intervenção; a falta de formação especializada dos professores, sobretudo dos directores de turma, para se relacionarem com as famílias e as comunidades; o uso de uma linguagem demasiado técnica e codificada; o pendor altamente burocrático do seu funcionamento e o "fechamento" à intervenção, opinião e crítica externa.

Aos constrangimentos criados pelos professores, pelos pais e pela escola, já apresentados, devem, ainda, ser acrescentados as potenciais dificuldades por parte do aluno. Este, enquanto elemento activo nesta trama e como canal de comunicação indirecta entre a escola e a família, tanto pode colaborar no desenvolvimento de uma relação positiva e construtiva, como, pelo contrário, pode desvirtuar as mensagens, manipulando-as na satisfação dos seus interesses, contribuindo, como refere Villas-Boas (2001, 109), para a criação de imagens menos positivas entre as duas partes. Montandon e Perrenoud (1987, 30), que nessa relação indirecta entre a escola e os pais designam o aluno como gobeetween, sublinham que ele pode subtrair todo o sentido às comunicações e relações directas entre a escola e a família.

Para além de todos os enviesamentos referidos, há a considerar o facto de não haver, tradicionalmente, uma cultura de comunicação, muito menos de participação e colaboração entre a escola e as famílias, o que faz com que se trate não raras vezes de um aparente diálogo de surdos. Segundo J. Lima $(2002,7)$, as relações entre pais e professores sempre foram assunto polémico, ora culpando os pais, nomeadamente, por ignorância passiva, ora acusando os professores por hostilizarem as percepções dos encarregados de educação. Não esquecendo o percurso longínquo e evolutivo que medeia o tempo em que o dever da escola era apenas informar os pais e o tempo actual em que a participação dos pais é um dever, persiste, todavia, entre pais e professores, um clima "caracterizado mais pela tensão e pela desconfiança mútuas, do que pelo consenso e pela cooperação" (ibid.).

De salientar que, segundo Teresa Sarmento $(2002,15)$ esta prática de costas voltadas por parte da escola e as famílias é tique herdado da tradição centralista portuguesa que remonta à reforma pombalina. Considera Nóvoa a esse propósito (1995, 32, 33) que, ao subtrair os professores à influência da igreja e das 
comunidades, é estabelecido um contrato entre os mesmos e o Estado que acaba por resultar na marginalização dos pais em relação à escola, justificada quer com a legitimidade exclusiva do Estado em matéria educativa, quer com a competência especializada dos professores nessa mesma matéria.

Contudo, como lembram Marujo, Neto e Perloiro $(2005,10,11)$, das relações de poder às de respeito e cooperação, da complementaridade ou confronto de estilos educacionais, algo tem vindo a mudar e, em nosso entender, muito mais deverá ser mudado. Acrescentam os autores que, apesar de a maior parte dos estudos revelarem que os pais e mães querem envolver-se na vida escolar dos filhos, o certo é que continua a haver dificuldades na sua efectivação, por não saberem fazê-lo, porque não têm tempo disponível, ou, ainda, porque estão face a uma escola que não estimula essas práticas. Paradoxalmente, a escola tem muitas vezes vindo a criticar o fraco envolvimento dos pais, revelando, simultaneamente, dificuldade em estimular e até, por vezes, aceitar e integrar esse mesmo envolvimento. Destas tensões, parece ter-se desenvolvido, no entanto, o sentimento comum sobre a necessidade de reformular esta ligação mútua. Os pais querem ser aceites como co-educadores pela escola e esta quer contar com os pais como parceiros intervenientes, activos e informados, no processo de aprendizagem. Mais do que nunca, pais e professores sentem hoje que necessitam trabalhar em conjunto para que as crianças tenham sucesso como pessoas e como alunos, tornando-se necessário, tal como afirma Silva (2003, 370), uma colaboração estreita e sistemática, promovendo aquilo que ele chama de "parentização docente" e "docentização parental.". Esta dinâmica de parceria e colaboração em proximidade, não necessita, nem deve, contudo, confundir ou subalternizar papéis. Antes se espera que seja desenvolvida de forma esclarecida, num contexto de "complementaridade" (Fonseca, 2005, 150), isto é, no respeito pelas esferas de influência, usando a linguagem de Epstein (1997).

Para tal, a escola deve assumir um papel preponderante no desenvolvimento de estratégias que envolvam todas as famílias. Falamos de estratégias que podem passar por acções de sensibilização e formação, apoios mais directos e individualizados que, pela sua função integradora, podem contribuir para o desagravamento da clivagem social na relação escola-família, tal como defende Avelino $(2005,76)$. Esta autora, considerando que a comunicação deve ser uma constante, apresenta um conjunto de pequenas estratégias que a escola pode utilizar para trazer os pais à escola e que vão desde reuniões temáticas de pais por turma ou por ano, com carácter periódico; entrevistas individuais no início do ano e sempre que se revele necessário; festas, convívios, teatros, visitas de estudo, a implementação de dias de...ao uso regular da comunicação escrita. Mendel (2007, 201-205) considera fundamental criar um lugar onde estes se possam encontrar, facilitando a sua participação na escola. Marques $\left(2001_{b}, 81\right.$, 82), para além destes, chama a atenção para a necessidade de melhorar os 
espaços em que os pais são recebidos na escola, nomeadamente pelos directores de turma. Uma outra estratégia que a escola pode desenvolver, no sentido de promover a colaboração dos pais, prende-se com a ajuda a dar às associações de pais no sentido de lhes facilitar o desempenho das suas funções de representação de todos os pais. Martins (2009, 85-101) aponta como uma das estratégias a levar a cabo, o permanente incentivo a dar aos alunos para facilitarem e incentivarem, eles próprios, os pais a colaborar com a escola.

No sentido do desenvolvimento desta aproximação, Marujo, Neto e Perloiro $(2005,12,13)$ exortam os pais para que não se limitem a delegar nos professores a responsabilidades educativas e falam das várias tarefas que podem e devem desempenhar no exercício das suas funções. Assim, os pais podem ser "apoiantes dos professores", facilitando a aprendizagem dos seus filhos em casa; ao aprenderem e concretizarem novas formas de educar, observando o comportamento dos filhos, são aprendizes; co-ensinando em casa conteúdos e formas de estudo ou atitudes, estão a ser professores; amigos, são-no, por exemplo, lendo aos filhos histórias, levando-os a museus ou preparando com eles materiais e projectos; ao participarem nas estruturas formais da escola, em que a sua presença é necessária e desejada, estão a ser parceiros na construção da política educativa. Ainda dentro da colaboração directa que os pais e os professores podem desenvolver em conjunto, os autores (id. 16,17) referem um conjunto de factores que em muito podem contribuir para o aumento da motivação e interesse das crianças em relação à aprendizagem, como seja uma percepção positiva de si mesmo e das suas competências; o acreditar no controlo sobre os acontecimentos da sua vida, em particular sobre o seu processo e resultados de aprendizagem, bem como uma imagem positiva e valorizada da escola e do processo de escolarização. Acrescentam, ainda, que estas atitudes se estimulam e desenvolvem através de estratégias que podem e devem ser partilhadas pela família, pela escola e pela comunidade e que passam, em primeiro lugar, pela criação de um ambiente familiar incentivador e modelo de vivências culturalmente ricas, de um acompanhamento optimista face aos resultados da criança, bem como de uma atitude de aprendizagem por parte dos pais; em segundo lugar pela criação de um ambiente escolar onde se pratique mais o incentivo do que a crítica e onde os professores funcionem como modelos e, por fim, o acesso a contextos culturais e literários na comunidade, tais como museus, bibliotecas, espectáculos de arte, etc.

Todavia, sabemos que esta é uma questão complexa que exige medidas de fundo e que só será possível concretizar tendo como base uma política clara e concertada de escola, por forma a que as estratégias desenvolvidas não corram o risco de ser atomizadas e até contra-producentes. Nessa linha, Pedro Silva (2009, 126-128) lembra que as escolas dispõem de espaços para promover o debate e definir tal política - a Direcção, o Concelho Geral, o Concelho Pedagógico ou o Concelho de Directores de Turma - e que o Projecto Educativo, o Regulamento 
Interno e o Plano Anual de Actividades são os instrumentos que devem funcionar como expressão pública e assumida dessa política de escola.

Pelo exposto, fica claro que os programas para melhorar o desempenho dos alunos através do envolvimento parental podem revestir diversas tipologias, devendo cada escola promover as estratégias que melhor se adeqúem à sua realidade. 


\section{Bibliografia}

AVELINO, O. (2005). Participação dos pais na vida da escola e no acompanhamento dos filhos - A importância da sintonia e da coerência. In Concelho Nacional de Educação (Org.), Educação e família (73-78). Lisboa: CNE.

BALLENATO, G. (2009). Educar sem gritar. Lisboa: A esfera dos Livros.

CANÁRIO, R. (2009). Escola/família/comunidade para uma sociedade educativa. In Concelho Nacional de Educação (Org.), Seminário Escola, família e comunidade (105 - 140). Lisboa: CNE.

CARNEIRO, R. (2001). Fundamentos da educação e da aprendizagem. 21 ensaios para o século 21. Vila Nova de Gaia: Fundação Manuel Leão.

COSTA, J. A. (1998). Imagens Organizacionais da Escola. Lisboa. Edições ASA.

DIAS, M. O. (2000). A família numa sociedade em mudança: problemas e influências recíprocas. In Gestão e Desenvolvimento, 9, 81-102.

DIOGO, A. M. (1998). Famílias e Escolaridade: Representações parentais da escolarização, classe social e dinâmica familiar. Lisboa: edições Colibri.

DIOGO, A. M., Serpa, M. D., Caldeira, S. N., Moniz, A. I. e Lopes, M. (2002). Escola \& pais de mãos dadas: um projecto de intervenção educativa. In Lima (org.), Pais e professores, um desafio à cooperação. (283 - 315). Lisboa: ASA.

FONSECA, F. A. (2005). Família e Educação. Porquê liberdade de opção educativa e formativa?. In Conselho Nacional de Educação (Org.), Educação e Família - Seminários e Colóquios (149-161). Lisboa: CNE.

FRANCO, F. M. M.; Villar, M. S.; Almeida, J. A. A. e Casteleiro, J. M. (2003). Dicionário Houassis da Língua Portuguesa. Lisboa: Círculo de Leitores.

LAWRENCE, E. S. (n.d.). As Origens da Educação Moderna. Lisboa: Editora Ulisseia Limitada.

LEANDRO, M. E. (2001). Sociologia da família nas sociedades contemporâneas. Lisboa: Universidade Aberta.

LIMA, J. Á. (org.). (2002). Pais e professores: um desafia à cooperação. Porto. ASA Editores II, S.A.

MARQUES, R. (1999). Modelos pedagógicos actuais. Lisboa: Plátano Edições Técnicas.

MARQUES, R. (2001 $)$ ). Educar com os pais. Lisboa: Editorial Presença.

MARTINS, E. (2009). Relação escola-família: o director de turma como mediador intercultural. In Concelho Nacional de Educação (org.) EscolaIFamíla/Comunidade, actas de seminário (pp. 85 - 95). Lisboa: CNE.

MARUJO, H. A., Neto, L. M. e Perloiro, M. F. (2005). A família e o sucesso escolar. ( $4^{\mathrm{a}}$ ed.). Lisboa: Edições Científica Editorial Presença. 
MENDEL, M. (2007). Lugares para os pais na escola - local de desafios parceria consciente. In Silva, P. (org.). Escolas, famílias e lares: um caleidoscópio de olhares. (201 - 210). Porto: Profidições.

MONTANDON, C. e Perrenoud, P. (2001). Entre pais e professores, um diálogo impossível?Para uma análise sociológica das interacções entre a família e a escola. Oeiras: Celta Editora.

NÉRICE, I. G. (n.d.). Introdução à Didáctica Geral, Dinâmica na Escola. Rio de Janeiro.

NÓvOA, A. (Coord.), Bosker, R. J., Brunet, L., Canário, R., Glatter, R., Good, T. L., Hutmacher, W., Scheerens, J. e Weinstein, R. (1995). As organizações escolares em análise. ( $2^{\mathrm{a}}$ ed.). Lisboa: Publicações D. Quixote/Instituto de inovação Educacional.

PORTO, M. (2005). Abertura de seminário. In Concelho Nacional de Educação (Org.), Educação e Família - Seminários e Colóquios (15-18). Lisboa: CNE.

SÁ, V. (2004). A participação dos pais na escola pública portuguesa. Uma abordagem sociológica e organizacional. Braga: Universidade do Minho.

SARMENTO, T. \& Marques, J. (2002). A escola e os Pais. Maia: Centro de Estudos da Criança - U.M.

SAVATER, F.(1997). O Valor de Educar. Lisboa: Editorial Presença.

SILVA, P. (2003). Escola - Família, uma relação armadilhada: Interculturalidade e relações de poder. Porto: Edições Afrontamento.

SILVA, P. (2009). O contributo da escola para a actividade parental, numa perspectiva de cidadania. In Concelho Nacional de Educação (Org.), Escola/Família/Comunidade, actas de seminário (115 - 140). Lisboa: CNE.

SOUSA, L. (1998). Crianças (com)fundidas entre a escola e a família... Porto: Porto Editora, Lda.

TRINDADE, R. e C., A. (2010). Educar e aprender na escola: questões, desafios e respostas pedagógicas. Vila Nova de Gaia: Fundação Manuel Leão.

ULMANN, J. (1982). La pensée educative compemporaine”. Paris: Vrin.

VILLAS-BOAS, M. A. (2001). Escola e Família. Uma relação produtividade aprendizagem em sociedades multiculturais. Lisboa: Escola Superior de Educação João de Deus.

VILLAS-BOAS, A. (2009). O contributo dos pais e da comunidade na melhoria do desempenho dos alunos. In Concelho Nacional de Educação Escola/Família/Comunidade: actas de seminário. (47 - 63). Lisboa: CNE. 